\title{
The Geographies and Politics of Gene Editing: Framing Debates Across Seven Countries
}

\author{
Morgan Meyer* and Frédéric Vergnaud \\ Mines ParisTech, PSL University, Centre for the Sociology of Innovation, i3 CNRS, UMR 9217, Paris, France
}

OPEN ACCESS

Edited by:

Michael Morrison,

University of Oxford, United Kingdom

Reviewed by:

Courtney Addison,

Victoria University of Wellington,

New Zealand

Brigitte Nerlich,

University of Nottingham,

United Kingdom

*Correspondence:

Morgan Meyer

morgan.meyer@mines-paristech.fr

Specialty section:

This article was submitted to

Politics of Technology,

a section of the journal

Frontiers in Political Science

Received: 27 June 2021 Accepted: 01 October 2021

Published: 25 October 2021

Citation:

Meyer $M$ and Vergnaud $F$ (2021) The Geographies and Politics of Gene Editing: Framing Debates Across

Seven Countries.

Front. Polit. Sci. 3:731496. doi: 10.3389/fpos.2021.731496
This article traces the contours and dynamics of the debates about the politics of gene editing. It does so by providing both a quantitative and qualitative analysis of the publications on the topic. We present a scientometric analysis of scientific publications; we discuss the geographies of gene editing by analysing the scales and spatial terms mobilised; and we undertake a lexicometric analysis of how debates are framed and the public is positioned. Our scientometric analysis of scientific articles shows that the governance and regulation of gene editing is discussed across an increasing range of disciplines and countries over the years. Along with this internationalisation and "transdisciplinarisation," we see a qualitative shift in the "grounding" of the debate: while initially, authors tend to reflect about gene editing, in more recent years, there are increasing calls to act upon current knowledge. Across the countries we studied (the United States, the United Kingdom, Germany, China, Australia, Japan, and Canada) our lexicometric analysis shows only a few differences in terms of how gene editing is discussed. While the general framing of the debate is widely shared, the differences that we observe concern for instance the applications or benefits of gene editing and the ways in which the importance of involving the public is worded. We hold that bringing together multiple methods allows a rich and multifaceted discussion of the politics of gene editing, and that this opens up fertile dialogues between geography, sociology and political science.

Keywords: gene editing, governance, quantitative methods, scientometrics, lexical analysis, geography

\section{INTRODUCTION}

Gene editing technologies, in particular CRISPR/Cas9, have been discussed in a significant number of articles, reports, position statements, and comments. While CRISPR sequences were first described in 1987, it is only since the 2000s that their ability to "edit" genes has been recognized and studied (the name CRISPR, for Clustered regularly interspaced short palindromic repeats, dates from 2002 and Cas9 is the name of an enzyme capable of cutting DNA). It must also been stressed that ideas and methods for introducing new genetic material into organisms and/or cells have become prominent since the 1970s (Morange 2017). CRISPR/Cas9 has been welcomed as a particularly precise, cheap and simple technology to modify genes, in particular in comparison to other gene editing techniques (such as those based on zinc finger nucleases or TALEN). At the same time, concerns have been raised about ethics, legal frameworks, risks, and new forms of inequality.

Gene editing has applications in domains ranging from health (i.e., to treat HIV, sickle cell disorders, cystic fibrosis or beta thalassemia) to agriculture (i.e., the creation of hornless cows, nonbrowning mushrooms and more resistant or nutritional plants) and the environment (to combat 
biodiversity loss and aid threatened species, control invasive species and pests). In 2015 gene editing has become highly visible beyond academic circles. Concerns about the use of gene editing to modify the human germline were sparked by an experiment on non-viable human embryos on the $\beta$-globin gene (Liang et al., 2015). In response, several groups of scientists called for a moratorium (Lanphier et al., 2015; Baltimore et al., 2015) and the technique was featured on the cover of various magazines (i.e., The Economist, Nature and Time) and in numerous press articles. The end of November 2018 marks the beginning of the most visible episode in the controversy to date. It was sparked by scientist He Jiankui, who announced via YouTube the birth of two babies he had genetically modified as embryos by using gene editing. The event has been widely and intensely discussed, both within and beyond the academic world. About half a year later, another scientist, Denis Rebrikov, announced in the journal Nature (Cyranoski 2019) his plans to produce gene-edited babies, which also led to criticisms and calls for moratoriums. Given the significance and contested nature of the technology, two international summits have been organized (in 2015 and in 2018) and the World Health Organisation established an expert panel on the governance of human gene editing in 2018. Regarding the use of gene editing in agriculture, international conferences have also been held (i.e., at the OECD in 2018) and the status and traceability of organisms modified via gene editing has become a hotly debated question: should they count as GMOs or not? The most visible controversy, however, concerns the use of gene editing for humans: while its use on somatic cells (which are not transmitted to descendants) is less controversial, its use on germline cells (which are transmitted) represents the crux of the debate (see Meyer 2020).

Within the social sciences, the debates around gene editing have been analysed from a variety of perspectives. Many articles have looked at the ethics and the governance of gene editing. Commentators have reflected on the first international summit on human gene editing and have called for more democracy and inclusivity, while also comparing the summit to the 1975 Asilomar conference on recombinant DNA (see for instance Jasanoff, Hurlbut and Krishanu 2015; Parthasarathy 2015; Frow 2015). Calls for an international observatory on gene editing have subsequently been made (Jasanoff and Hurlbut 2018). The governance of gene editing in the field of agriculture has also been examined, regarding differences across EU member states (Meyer and Heimstädt 2019), regarding the impasse in EU policy (with actors being either proponents or opponents of the technology) and how to get out of it (Macnaghten and Habets, 2020), and concerning NGO's views on the use of gene editing in plants (Helliwell et al., 2019).

There has also been considerable scholarship on communication and public debate. The recent special issue titled "Communicating gene editing: Agriculture, humans, and the environment" edited by Brossard and Scheufele in Environmental Communication (2020) provides a broad overview of public debates, opinions and engagements, and discusses various forms of communication about gene editing. Several authors have focused their analysis on the controversy sparked by He Jiankui, and studied how responsible research is demarcated from irresponsible research (Meyer 2018), what philosophical traditions can be mobilised for analysis (Yan and Mitcham 2020), and the public reactions on social media (Zhang et al., 2021). While much academic work has looked at the politics, publics, ethics and controversies around gene editing, there have also been some studies analyzing the continuities and discontinuities of gene editing in relation to existing biotechnology (Martin et al., 2020) as well as patenting (i.e., Mali 2020).

In our paper, we ask the following questions: what are the contours and dynamics of the debates about the politics of gene editing? How are these debates framed? Our paper thus aims to contribute to the growing literature on gene editing in two ways. First we offer a geographical analysis of gene editing. While many articles have discussed gene editing in a given country or territory (i.e., the EU) and many authors called for "global" and "international" governance and regulation, there are hardly any articles that address the geographical aspects of gene editing. Here, scholarship from science studies and the geography of science (Gieryn 1983, 1999; Shapin 1998; Livingstone 2005) is helpful. Inasmuch as science studies have shown that "science must take place somewhere" (Livingstone 2005: 100) and that "the global is situated" (Law 2004: 24), we hold that this also rings true for the governance and regulation of science. We hold that the governance and regulation of science is also spatially situated and arguments about their national, international or global nature need to be analysed and not taken for granted. Second, we contribute to the existing literature by undertaking an analysis that is both quantitative and qualitative. Apart from surveys about the cost of regulating gene edited crops (Lassoued et al., 2019) and about people's perceptions of gene editing (Kato-Nitta et al., 2019), the use of quantitative methods to analyse the social and political aspects of gene editing has been extremely rare. And, to our knowledge, the use of mixed methods has been non-existent to date. We thereby also respond to recent calls (Leydesdorff et al., 2020; Cambrosio et al., 2020) for a renewed dialogue between qualitative and quantitative/computational science studies, a dialogue that has begun to emerge in studies about synthetic biology or nanotechnology for instance, but been virtually non-existent regarding gene editing.

Our paper is structured as follows. In the next section we explain the methods that we used. Thereafter we present our results in four sub-sections, each responding to a specific question: what are the publication trends across countries, disciplines and time (3.1)? How are debates about gene editing framed in scientific publications and in reports - what are the main themes being discussed (3.2.)? What are the geographies of gene editing (3.3.)? How is the public positioned (3.4.)?

\section{METHODS}

We built our empirical corpus by compiling three kinds of documents: scientific publications, institutional reports and conference reports. First, in order to collect relevant scientific publications, we searched the Web of Science database with 
specific key-words in the field "topic": "regulation," "governance," "politics" in combination with "gen* editing" (a search in "all fields" yields too many unrelated results, for terms like "regulation" can be present in the affiliation of an author). Our search yielded 358 results (we used version 5.35 of the Web of Science, before its update on the seventh of July 2021). For our analysis, we relied on the categorizations of the Web of Science, such as "research axes." Research axes have been created to unify the systems of classification within the Web of Science databases and are automatically attributed to journals. Even though such categories do have their limits (as any classification system has), they are commonly used in scientometric studies and they are considered as a key classification system of current scientific journals - according to Wang and Waltman (2016), the journal classification system of the Web of Science is more accurate than the one of Scopus.

Second, we collected reports on gene editing published by various institutions, such as ethics committees, advisory groups or scientific academies (our criteria for inclusion was that they need to specifically deal with gene editing and that they have to be reports, and not items such as statements or press releases). We searched for these reports through several sources (i.e., resources listed by the WHO working group on gene editing, references listed in reports and in academic papers, etc.). We then selected the reports stemming from the seven countries that we selected for our lexical analysis (see below), which left us with eight reports from four countries (being unable to find reports from China and Japan and having to exclude a report from Canada). Third, we have collected the written reports from the two most prominent conferences held so far in the field: the international summits on human gene editing held in 2015 and in 2018. While at first look, both summits resemble any other international academic conference, they are quite particular events: they were organized in response to a pressing issue, they were very publicized (in academic circles, but also in the media), they issued final statements and their audience exceeded well beyond the scientific community. So while other international conferences about gene editing have been held, the summits are key sites in which the politics of gene editing are made explicit and publicly discussed.

It is important to stress the differences between these three types of documents in terms of style, format and readership. The first ones are written by individual scientists and are published in academic journals, while the second and third ones are authored by various kinds of institutions (with various kinds of scientific, political and/or moral jurisdictions) and made available online. And while scientific publications and institutional reports present a rather coherent set of arguments or positions, the reports from the summits provide a more heterogeneous picture by summarising the discussions. This diversity does, however, allow us to embrace a particularly broad space of discussion, by looking at debates across disciplines and countries, and by embracing both the academic world and the policy world.

We read the abstracts of the 358 articles and we discarded 26 articles that did not explicitly address the regulation and governance of gene editing. We then decomposed our analysis of the 332 remaining articles into two steps. In the first step, we
TABLE 1 | Comparison between country distribution by continent of the totality of the authors of our original corpus of 300 publications and country distribution by continent of the 241 remaining publications (after removing the 59 co-authored publications).

\begin{tabular}{lcc}
\hline & $\begin{array}{c}300 \text { publications: \% } \\
\text { of authors } \\
(\boldsymbol{n}=\mathbf{8 0 9 )}\end{array}$ & $\begin{array}{c}\mathbf{2 4 1} \text { publications: \% } \\
\text { of authors } \\
(\boldsymbol{n}=\mathbf{5 1 4 )}\end{array}$ \\
\hline North America & 38.8 & 42.0 \\
Europe & 36.7 & 28.6 \\
Asia & 12.1 & 14.8 \\
Oceania & 6.7 & 7.4 \\
South America & 3.3 & 5.3 \\
Africa & 2.3 & 1.9 \\
\hline
\end{tabular}

focused on a classical scientometric analysis. We first set aside the 21 articles from the year 2021, to be able to compare full years. We used the 311 remaining articles to statistically describe their distribution by type of publication, by discipline, and by year. In a second step, we focused on the thorny problem of assigning a unique national origin to the collected articles. For this, we exploited the "addresses" field provided by the Web of Science, which indicates the academic affiliation of the author(s) of an article. This field can indicate the academic affiliation of an author, the academic affiliation of a group of authors, or the different academic affiliations of the same author.

Attributing a country to a scientific publication by using the academic affiliation of its author(s) is a common procedure in scientometric studies. While this does not allow inferring the advancement of scientific fields in a country, it at least allows us to describe the growth dynamics of certain scientific fields in a given country (Monroy and Diaz 2018). On the other hand, a lexical analysis is a statistical method that aims to classify statements in a way that represents their broad dimensions (Lahlou 1994). In other words, using a lexical approach on a corpus of texts amounts to describing "about what" authors talk in this corpus (Fallery and Rodhain 2007).

By extension, in our study, cross-referencing the country of a scientific publication with the lexical analysis of its content (its abstract) thus makes it possible to describe how the content of this publication (the governance and regulation of gene editing) is discussed within the country of this publication (the country of affiliation of its authors). There remains the question of coauthorship: in which country does one classify a publication if co-authors have their affiliations in different countries? Comparing the country distribution by continent of the totality of the authors of our original corpus of 300 publications to the country distribution by continent of the totality of the authors of the 241 remaining publications (after removing the 59 publications with co-authors), we obtain the following results (see Table $\mathbf{1}$ ).

If we remove co-authored publications, we find roughly the same proportions of publications per continent, except for Europe, which tends to prove that co-authorship does not have a significant influence on our corpus of data. On the subject that interests us, the publication dynamics of the countries remain almost the same with or without co- 
authorship. The table also shows that on the subject of the governance and regulation of gene editing, small scientific communities do not need their larger counterparts to publish on the subject: the 2-point difference found in South America and the 2.7-point difference in Asia even tend to demonstrate a slight movement of autonomy of these countries regarding the subject.

The case of Europe is different, since the proportion of authors decreases by $8 \%$ when we remove publications with co-authors from our corpus. We can interpret this as being due to an important integration of European countries in science. Already in the early 2000s, a scientometric study described the increase in the density of relations between scientists in European countries, driven by the success of European R\&D programs (Frenken and Leydesdorff 2004). In 2008, another study concluded that the Europeanization of co-authorship of European scientists was more important than its internationalization (Mattsson et al., 2008). This movement also appears in our study, and tends to demonstrate an important intra-EU transnational partnership of European authors on the subject of the governance and regulation of gene editing. Nevertheless, in order to distinguish differences between European countries, we have, in what follows, chosen not to group European countries into a single entity.

We therefore constituted our different corpuses via three phases. First, in order to present an analysis of the distribution by country of the authors of the publications collected from 2013 to 2020, we subtracted those articles for which the "addresses" field was empty (an inevitable step in scientometric analyses). 11 articles were thus subtracted, leaving us with 300 articles. Second, in order to assign a single country of affiliation to our articles, we removed articles that were written by several authors from different countries: 59 articles were removed, leaving us with 241 articles. Third, we wanted to cross-reference the "country" of an article with the lexical content of its abstract. Thus, in order to constitute a corpus for a more qualitative analysis, we took as a basis the original corpus of 332 articles, which includes articles from 2021, and subtracted 12 articles without "addresses," 26 articles without abstract, and 64 articles written by several authors from different countries, leaving us with 230 articles. Of these 230 articles, $33 \%$ are from the United States, $8.3 \%$ from the United Kingdom, 5.2\% from Australia, and 4.8\% from each of the following countries: Canada, Japan and Germany. A total of $60.9 \%$ of the articles are thus published by authors of the aforementioned countries.

In order to restrict our analysis to a small and manageable group of countries, while keeping a sufficient number of abstracts available for our analysis, we decided to select for the lexical analysis only articles from countries that published more than 10 articles: the United States (76), the United Kingdom (19), Australia (12), Canada (11), Japan (11), and Germany (11). However, since China is an important actor regarding the governance and regulation of gene editing, we decided to also include its articles ( 8 articles, equaling to $3 \%$ of the total number of articles). This eventually led us to a corpus of 148 abstracts. We are aware of the limitations implied by these decisions, but we consider that the present study represents a first synthesis of its kind, laying the groundwork for more studies to come, that could analyze more systematically articles published from all over the world on the subject.

We also contend that our corpus comprises articles that cover very different fields of application (agriculture, the environment, human health). We have analyzed them together, in order to start with-and be able to provide a picture of - gene editing as a whole. We did not differentiate our corpus regarding disciplines or fields of application before our analysis, but we wanted to let these differences emerge. Further work could thus examine to what extent findings vary when the corpus is divided according to applications and/or disciplines.

In order to do our lexical analysis, we used IRaMuTeQ. IRaMuTeQ is a program for the multidimensional and statistical analysis of a corpus of text (Ratinaud, 2021). It is based on the Max Reinert classification method (Reinert, 1983; Reinert, 1986; Reinert, 1990), an analysis which is based on a hierarchical descending classification. While IRaMuTeQ offers three classification methods, we have used simple classification in this article (see Supplementary File SA). This statistic classification takes place on a segment of text, and makes it possible to obtain a near exhaustiveness of the sentences of the study corpus in the final classification since the terms are compared with each other within the entire text. We build here on our previous study of online discussions about do-ityourself biology via IRaMuTeQ (Meyer and Vergnaud 2020).

In parallel to our scientometric and lexical analysis, we did two qualitative rounds of analysis to examine the spatial dimensions of our corpus. First, the content of the reports from the two international summits on human gene editing was analysed qualitatively. Themes dealing with geography and space were analysed - and the content of both reports have been compared. To do so, a "selective" coding of the reports was done, by defining a core variable (space/geography) without coding any other dimensions (on coding and categorization see Kelle 2010; Thornberg and Charmaz 2014). This was done manually: all the words or groups of words that refer to space were underlined, compared and analyzed and then divided into categories. Three large categories were defined: "international context," "fragmentation and variation across countries," and "national contexts." As the kinds of arguments within the first category varied importantly, they were further divided into four subcategories: "dialogue," "governance," "techno-science," and "values/ethics" (see Table 2). This way of coding the data allowed us to be able to identify and examine the range of arguments used. At the same time, it also allowed us to be able to see to what extent specific categories or subcategories differ between 2015 and 2018 .

Second, we did a qualitative analysis of the active word forms in our corpus ("active" word forms are nouns, adjectives and adverbs and thus exclude "supplementary" word forms like pronouns, prepositions, etc.). To do so, we read through all the 2,915 active forms to search for words describing space in one way or another. We ended up with two separate lists of words. In our first list we included words about concrete aspects of geography, which divide into three categories: the international level, the national level and the European level. In our second list, we included terms that deal with space in more metaphorical and/ or abstract sense (such as "line," "barrier," "space," and 
TABLE 2 | Main geographical themes (in bold) - and examples of quotes - in reports of the international summits on human gene editing held in 2015 and in 2018.

\section{5 summit}

Dialogue: summit "brought together more than 500 people from around the world" and "Experts from many parts of the world"; "global dialogue," "international community," "global discussion"

Governance: "governance is becoming increasingly international," "Governance (...) is now crossing geographical borders (.. . governance is no longer just local, but is becoming a network of nations working together"; Proposal of "international ban on germline gene editing for reproductive purposes can be secured through the United Nations and regional bodies can prepare internationally binding regulations"

Techno-science: "CRISPR-Cas9 is being used in laboratories around the world," "the human genome is shared among all nations,"'genetic alterations (...) would not remain within any single community or country," "It's no longer possible to control technologies by the laws of one country"

$-$ "governance can differ among countries," "representatives from Nigeria, Germany, France, Israel, South Africa, Sweden, and India highlighted the many ways in which policies (...) vary among nations (... and) that the needs of countries vary dramatically" "countries have in place provisions that act to prohibit germline gene editing," "people will go to whichever country has it," "many nations have legislative or regulatory bans on germline modification," "each nation ultimately has the authority to regulate activities under its jurisdiction"

\section{8 summit}

Dialogue: summit brought together 500 people "from around the world" and was viewed by "visitors from over 190 countries"; "international discussion"; "international forum," "need for the global scientific and medical communities to continue to work together," dialogue between "academies around the world," "international scientific community"

Governance: "the organizing committee calls upon national academies and learned societies of science and medicine around the world to continue the practice of holding international summits to review clinical uses of genome editing, to gather diverse perspectives, to inform decisions by policymakers, to formulate recommendations and guidelines, and to promote coordination among nations and jurisdictions" $-$

values/ethics: "global ethical code of conduct," "universal values," "global standard"

"differences in local contexts, values, and opinions"

Contexts in Japan, sub-Saharan Africa, China, France, India, Australia, Singapore, and Hong Kong discussed; "in China an extensive regulatory framework governs genome editing"; surveys in Australia and public participation in the United Kingdom and China mentioned; "a Chinese researcher," "a researcher in China," "a particular problem with the governance of human genome editing in China," "the researcher did not follow guidelines (...), or other international norms" "landscape"). For the terms of our second list, we rechecked in our corpus how they were specifically used, that is, in combination to what other kinds of words-and in what sense - they were used.

Rather than doing two separate rounds of analysis (one quantitative, one qualitative) we moved back and forth between a quantitative and qualitative analysis (see Akrich 2019). Both were brought into dialogue in several ways: we were able to validate and extend our lexical analysis of the reports of the international summits by theorizing how the debate became more "grounded" over time; our statistical analysis yielded a list of active forms that we reinterrogated qualitatively concerning the use of terms referring to geography; and, in more general terms, we did not stop at identifying the framings of the debates about gene editing, but also the politics of these framings (by discussing issues such as democracy and the inclusion/exclusion of the public).

\section{RESULTS}

\section{Scientometrics Article Types and Disciplines}

About $60 \%$ of the 311 publications are journal articles, $30 \%$ are either editorials or reviews, and the remaining $10 \%$ include items

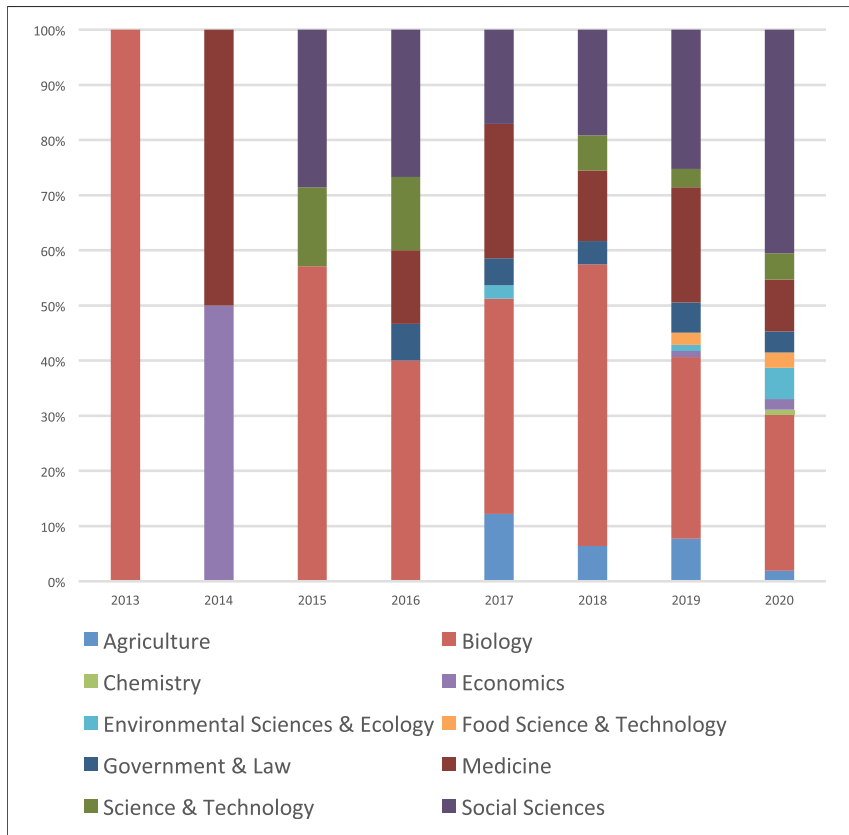

FIGURE 1 | Evolution of research areas from 2013 to $2020(n=311)$. 


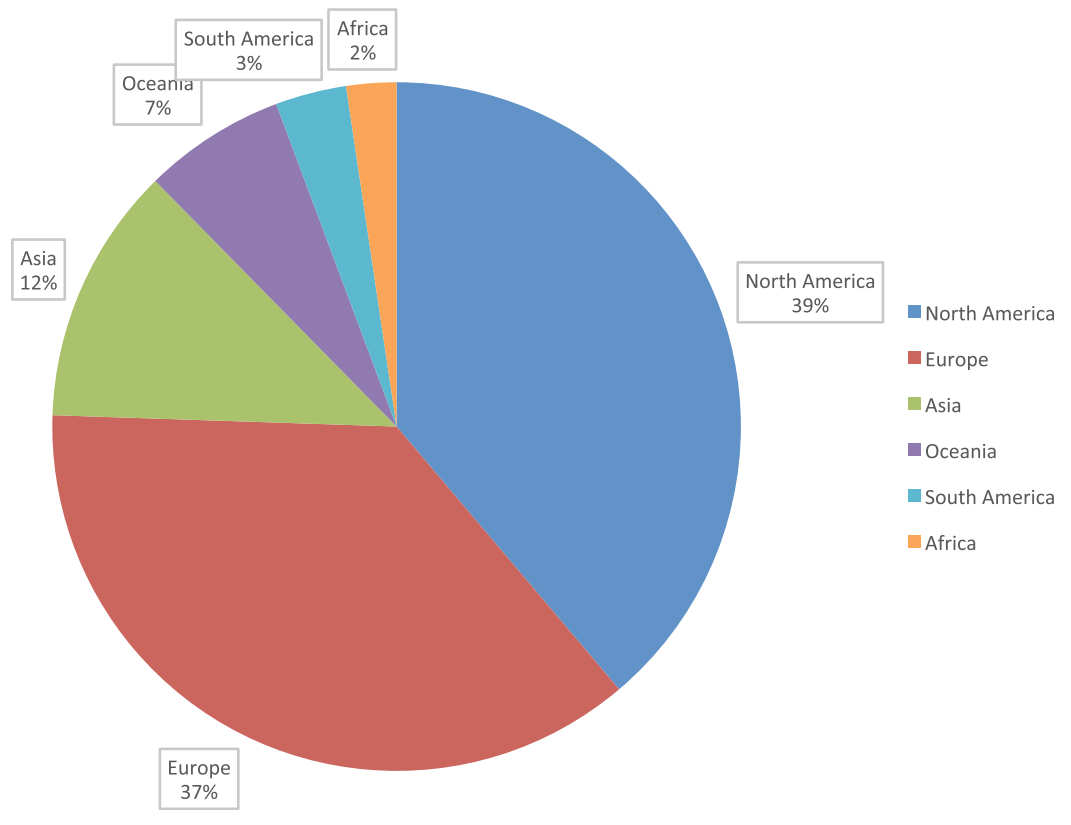

FIGURE 2 | Distribution of the academic origin of authors $(n=809)$.

such as book chapters, meeting abstracts, and news items. The disciplines most represented are "social sciences - other topics" (33\%), "biochemistry and molecular biology" (9\%), "agriculture" (7\%), "biotechnology and applied microbiology" (7\%), "genetics and heredity" (5\%), "plant sciences" (4\%). While the social sciences represent about a third of the corpus, the natural sciences represent two thirds. Within the natural sciences, genetics and molecular biology are more prominent than fields such as medicine or environmental sciences for instance.

If we regroup disciplines (such as biology, biochemistry, biotechnology, etc.), in order to see evolutions more distinctly, several trends are visible. The proportion of biology articles decreases significantly: it is divided by almost two, from $57 \%$ in 2015 to $28 \%$ in 2020 (see Figure 1). New fields are also emerging, such as agriculture and health care sciences in 2017 and food sciences in 2019. During the same period, the proportion of the social sciences also varies. While it has decreased between 2015 and 2017 (from 28 to 17\%), there has been an increase from 2018 onwards, with 25\% in 2019 and $40 \%$ in 2020. We thus see that over time, discussions about the governance and regulation of gene editing spread to a broader range of disciplines and become less dominated by biology. While the natural sciences still comprise most references, the debate becomes more multifaceted and more application-oriented over time.

\section{Evolution Over Time}

Only four articles have been published in 2013 (2) and 2014 (2). In 2015-2016, we observe a twofold increase of the number of publications, and a threefold increase between 2016 and 2017. While the years 2017 and 2018 are relatively stable in terms of output, we see another doubling in 2019, and a slight increase in
2020. There are thus two significant increases after relatively little interest in the regulation and the governance of gene editing in the period 2013-2014: the first increase (2015-2017) being arguably caused by the controversy sparked by Liang et al. (2015) and the second increase (2019-2020) being a reaction to He Jiankui's experiments.

\section{Evolution Across Geography}

About half of the authors of the publications stem from four countries: the United States, the United Kingdom, Canada and Australia. One third of the publications are written by authors from the following nine countries: Germany, China, Japan, Spain, Netherlands, Italy, France, Belgium and Sweden. If we look at publications across continents, we see that most authors are from North America (38.8\%) and Europe (36.7\%), a smaller number of authors stem from Asia (12.1\%), and only a few articles have been published by authors from South America (3.3\%) or Africa (2.3\%) (see Figure 2). Between 2013 and 2020, we observe two trends (see Figure 3). There are new countries present in the corpus. Until 2016, there are principally publications from authors in Europe (France, United Kingdom, Germany, Spain, Belgium, Norway, Poland), North America and Japan. In 2017, Europe enlarges (with authors from Finland, Italy, and Sweden joining), South American authors join (Argentina, Brazil), as well as Asia (Singapore, India). In 2018, we see another extension in Europe (with Denmark, Belgium, Iceland, Lithuania, Norway and Serbia), the inclusion of African authors (Kenya, South Africa), and an extension of Asia and the Middle East (Pakistan, Oman, China). From only four contributing countries in 2015, the number rises to 21 in 2017, up to 38 countries in 2020. At the same time, there is a slight decrease regarding North America. There has thus been an 


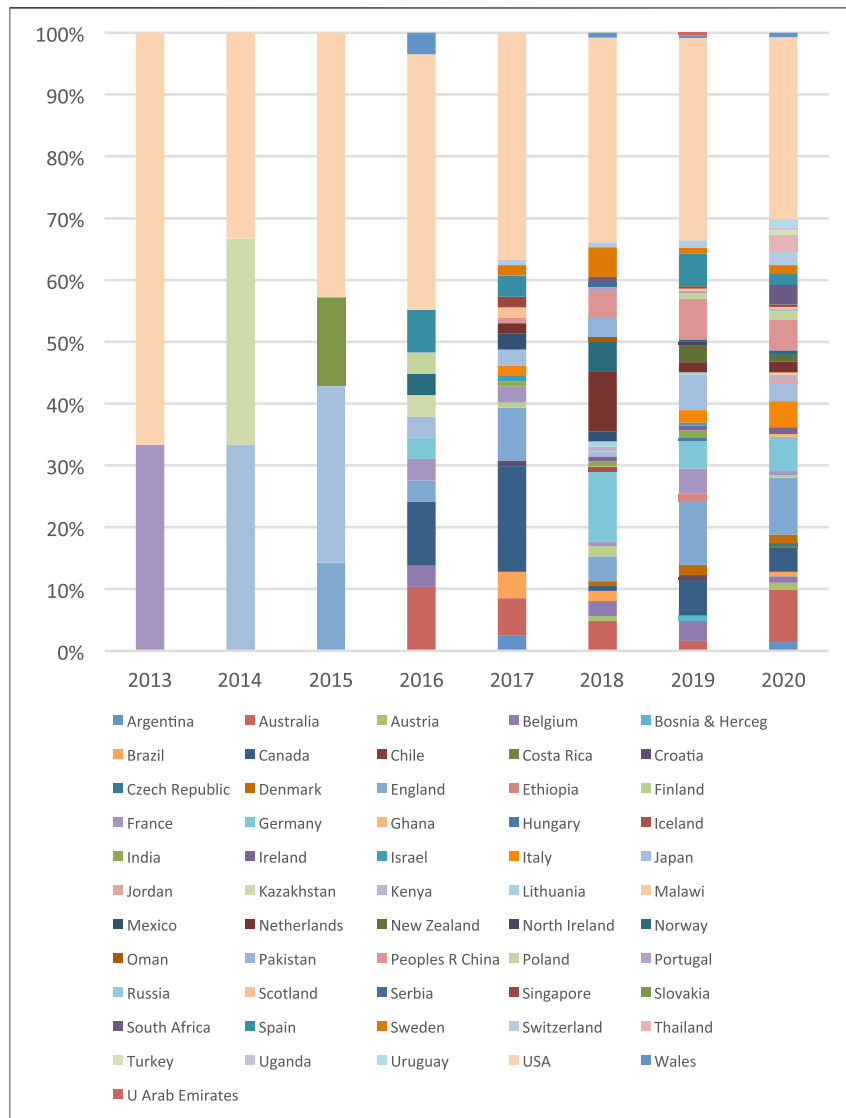

FIGURE 3 | Evolution of the institutional origin of authors from 2013 to $2020(n=809)$.

internationalisation, with North America being less prominent, and new countries joining the debate. This trend is visible in many other domains, where we see fewer publications from hegemonic countries, and new (i.e., Asian) countries increasingly present (see Kumari 2006; Glänzel et al., 2008). However, the key locus of scientific production is, still, Europe and North America. Despite the fact that there has been an internationalisation of the debates, they cannot be qualified as international.

\section{Lexical Analysis}

\section{Summit Reports}

Two international summits on human gene editing have been held to date: the International Summit on Human Gene Editing held in Washington in 2015 (National Academies of Sciences, Engineering, and Medicine, 2017) and the Second International Summit on Human Genome Editing (National Academies of Sciences, Engineering, and Medicine 2019) held in Hong Kong in 2018. We considered the reports of these two summits as a unified and coherent corpus. Our analysis of both reports provides a fairly comprehensive inventory of issues related to gene editing in the world. Three main themes are addressed: the description of the method and the targets of gene editing, governance and regulation, and the role of the public.
In 2015, the participants focused extensively on the method of gene editing and on the variety of applications: DNA, cells, blood, embryos, sperm cells, the fetus, the body. The possible benefits of its use for the treatment of certain genetic diseases or viral infections were discussed, as well as the risks of genetic modifications on future generations. Nevertheless, these future generations were discussed more succinctly, and described as being largely dependent on the policies and regulations of each country (given that governance frameworks are not uniform across countries). The organising committee wished to assess these dangers in order to comply with "ethical rules." It also hoped for the emergence of a public debate, in order to establish a "network of nations" and an international regulatory framework. In 2018, the fields of application of gene editing were discussed again, for instance in the treatment of certain genetic diseases, such as Duchenne muscular dystrophy. But it was also argued that the discussion needed to move beyond the potential targets of gene editing, be it the cell or the embryo, and look beyond cell therapies and clinical trials. For there are patients, parents, and people to be considered: the public is to be taken into account. The role of the public, and its engagement through dialogue and discussion, was thus discussed. The organizing committee also recognized the lack of transparency of certain research in progress, and pleaded for the adoption of ethical considerations in research using gene editing.

We also carried out a qualitative analysis of both reports, in order to examine more specifically the geographical arguments and terms present. In both reports, three sets of geographical arguments stand out (see Table 2). First, the international nature of the debate is prominent. The summit is called "global" and "international" and was attended by people from "around the world." At the same time, the governance of gene editing is qualified as "international," requiring nations to "network" and "coordinate." Second, variation and fragmentation across nations are also stressed, with the term "difference" being frequently used. Third, and relatedly, national contexts are also specified. Some nations have regulatory frameworks that allow or prohibit gene editing, and there have been surveys and engagement exercises in various countries.

Despite these similarities, there are two noteworthy differences. "Ethics," "values," "guidelines," and "norms" are featured more prominently in the report of the second summit - which has also been revealed through our lexical analysis above. While in 2015, discussions about governance and regulation were rather general and abstract, in 2018 they were discussed in relation to more tangible entities, such as written guidelines, independent assessments, scientific institutions, national regulatory authorities, prohibitions, etc. rendering the practical ramifications of governance/regulation more explicit (see Meyer 2021). We see a shift here in the "grounding" of the debate: in 2015, the scientific community came together to reflect, in 2018, calls were made to act. In 2015, the discussion was more hypothetical, with discussions about potential applications, possible benefits, and future public debates. In 2018, however, with the news that human gene editing had become a reality, we see discussions that are much more centered on decision-making with institutions and regulatory authorities being called to act. 
TABLE 3 | Institutional reports analyzed.

Australian Academy of Sciences (2017). Synthetic gene drives in Australia: Implications of emerging technologies. Canberra: Australian Academy of Sciences.

Deutscher Ethikrat (2017). Germline intervention in the human embryo. German Ethics Council calls for global political debate and international regulation. Berlin: German Ethics Council.

Deutscher Ethikrat (2019). Intervening in the Human Germline. Berlin: German Ethics Council. Nuffield Council on Bioethics (2016) Genome Editing: An Ethical Review. London: Nuffield Council on Bioethics.

Nuffield Council on Bioethics. (2018). Genome Editing and Human Reproduction: social and ethical issues. London: Nuffield Council on Bioethics.

National Academies of Sciences, Engineering, and Medicine (2017) Human Genome Editing: Science, Ethics, and Governance. Washington: National Academies Press. National Academies of Sciences, Engineering, and Medicine (2019). Heritable Human Genome Editing. Washington: The National Academies Press.

The second notable difference between the two summits is the fact that China and the work of He Jiankui are discussed at length at the second meeting. He Jiankui's announcement of the birth of gene-edited babies happened at the eve of the second summit, which caused a major controversy. In the report of the summit, we read of "a Chinese researcher" and "a researcher in China," and of "a particular problem with the governance of human genome editing in China." The issue is that "the researcher did not follow guidelines (...) or other international norms." The summit became a site in which He Jinakui was singled out and a clear boundary was drawn between responsible science, produced in a transparent and open way, and, on the other hand, irresponsible science, produced in secret.

\section{Institutional Reports}

We then analysed the reports published by national science academies and ethical councils. We were able to analyse four countries of our corpus (Germany, Australia, the United Kingdom and the United States, see Table 3) - we had to exclude the report from Canada because it does not represent a "national" view (the report is not written by a national institution, but co-authored by one university and a private actor), and we were unable to find reports from China and Japan. The themes in the reports mirror the themes addressed in the two summits, but show nonetheless variations in the four countries we studied.

The description of the method of gene editing and the variety of targets and applications is taken up in unison by the reports we have analyzed. The reports generally mention the importance of taking into account the public, but there are nuances to be noted nonetheless. The US reports call for "citizens" to give their opinion, by setting up forums, debates and committees to create a dialogue with the public, to promote their engagement and participation. This mobilization should provide recommendations to be addressed to policy makers in order to create and legitimize a national policy. The UK reports tackle the subject in the form of the "societal question." Debates, dialogues, and conferences are desirable, but a certain "morality" must accompany the decisions taken in these places, which should lead to acceptable "standards" ensuring "well-being," dignity and human rights of the concerned actors (especially children). The German reports raise the question of justice. Genetic improvement or modification must be done in a spirit of fairness, equality and solidarity, in order to avoid discrimination and inequalities. Finally, the Australian report, which is the least talkative on the question, envisages a public consultation, but with the aim of making the scientific community and its actions transparent to the eyes of the Australian population.

The issue of governance and regulation is found in all the reports studied, with here again a few differences. The US and German reports both advocate collaboration, close cooperation between national and international institutions. A framework for the implementation of harmonized standards should lead to a convergence of national views (i.e., national laws and regulations, national academies of science and ethical councils, and international standards and regulations). The UK and Australian reports rely more on the existing national legal system. The UK reports, although they talk about an ethical and democratic governance, do not refer to a transnational vision that would supervise and advise the political, scientific and public stakeholders in the country. Likewise, discussions in the Australian report remain within the remits of the national legal system, suggesting a review of existing Australian regulations to take into account new methods of gene editing.

Some national reports mention subjects that we do (almost) not find in other reports, thus revealing some national specificities (which we will address in the next subsection, in our analysis of scientific articles). This is the case, for instance, of the Australian report, the only report to mention the benefits of gene editing in the fight against certain species of invasive plants and certain harmful insects (such as mosquitoes). The report also sees gene editing as a means of reducing the use of pesticides and thereby improving the quality of the environment and public health. The German reports, on the other hand, show a stronger focus on justice, equality, freedom and solidarity between individuals. It is argued that gene editing must be available to everyone, to avoid new discriminations. Finally, the UK reports evoke the consequences of gene editing on the economy and the market, with potentially new investments and funding streams and gains in productivity.

In conclusion, both the international summits and the national reports that we analyzed converge in a panoramic vision of the challenges of gene editing: they comprise precise descriptions of the scientific state of the art of the method and its different areas of application; they raise the issue of the kind and scale of governance needed; and they call for ethical and social dimensions to be taken into account. National specificities appear rather at the margins. In order to examine if and how these specificities are discussed and reflected in different countries, we now examine scientific articles. 


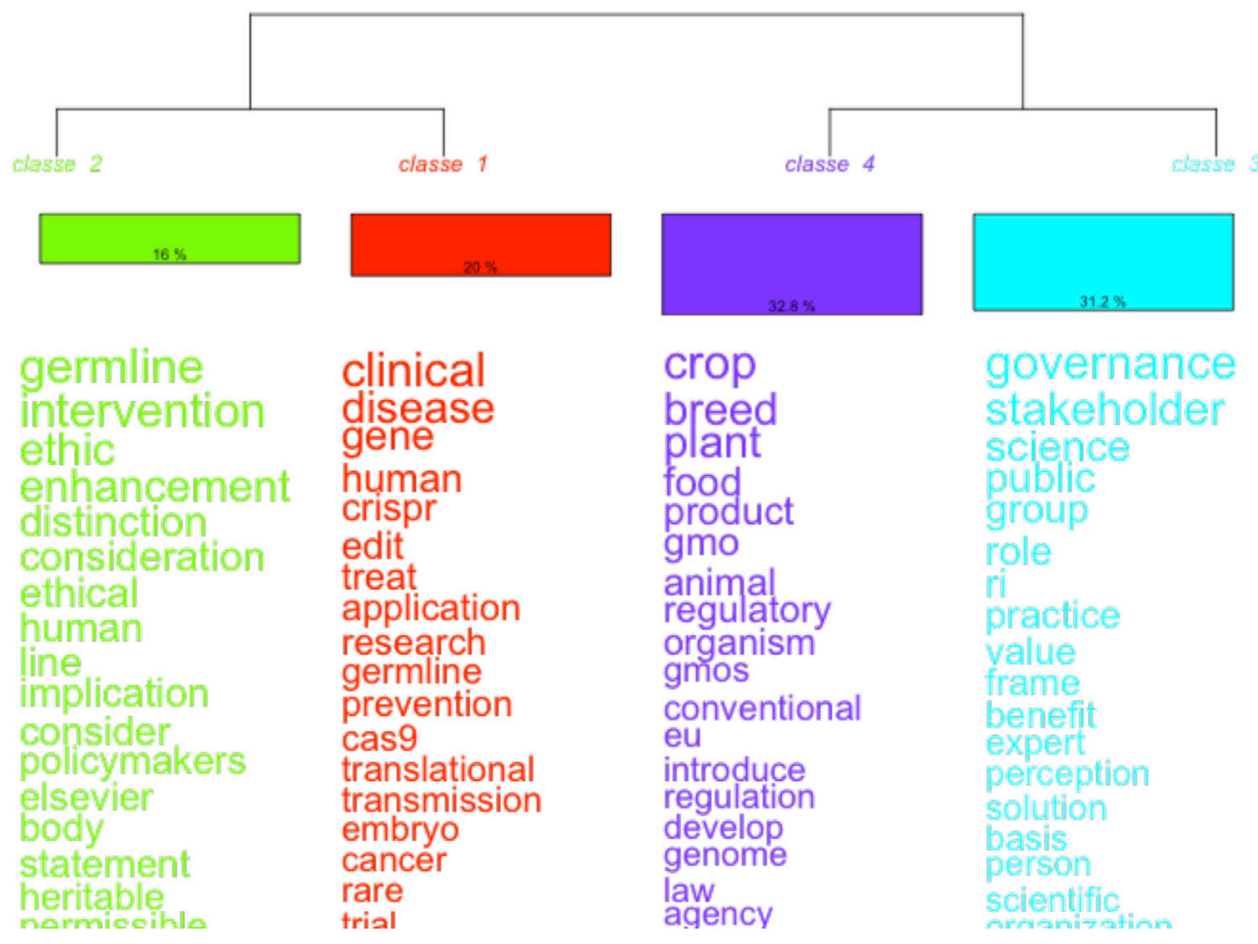

FIGURE 4 | Lexicometric analysis, via IRaMuTeQ, of the whole corpus of article abstracts (see Supplementary File SA for all IRaMuTeQ results) ( $n=148$ ). The given percentages refer to the size of the classes, expressed as a percentage of the classified corpus. In the text, we discuss them in descending order ("classe 4 ," then "classe 3," then "classe 1," then "classe 2").

\section{Scientific Publications}

In order to provide a general overview that can be compared to the above analysis of the summits and the reports, we assembled the abstracts of the 148 publications that we selected into a single corpus. The lexical analysis of this corpus reveals a classification into four main themes (see Figure 4).

The first theme revolves around the enhancement of existing crops or new varieties of genetically modified crops, new forms of animal breeding, and their impact on agriculture and human livelihoods, security and consumption: how will farmers adapt to new modes of production? Are GMOs the solution to food safety? Will consumer's preferences change regarding GMOs?

The second theme deals with the governance of gene editing, and the role of the public. National systems, transnational systems, institutions, scientific organizations, and the public face different options, interests and values that should be brought together via new forms of interaction. Terms such as "responsible innovation," the "precautionary principle," "debate" and "discuss" reveal that the debate around gene editing should take place in a more open and transdisciplinary way, by involving various stakeholders and members of the public. What is at stake here is the inclusion of lay expertise as a supplement of established scientific expertise [a theme discussed by a number of science studies scholars, including Callon (1999) and Epstein (1995)].

The third theme revolves around the technological advances that gene editing represents when applied to medicine, gene therapy, the prevention and treatment of rare genetic diseases or cancers.

Finally, the fourth theme reflects the "legal and ethical challenge" posed by human enhancement using gene editing. Whether or not to cross the "red line" of modifying the human genome, and thus interfere with the genetic heritage, is a fundamental issue that lies at the heart of lawmakers' and policymakers' concerns. These questions also confront the autonomy of parents regarding their choice to resort, or not, to the editing of a child's gene. A "societal, ethical and scientific debate," as well as the development of "ethical standards" must be, so the argument goes, the goal sought by institutional, scientific and societal stakeholders. The second and fourth themes reflect some of the most visible tensions and frictions in the recent controversy around human gene editing, that is, the discussion about "where to draw the line" and what choices to make when it comes to using gene editing for therapeutic purposes, or even for enhancement.

This is the general overview of the themes discussed by the scientific authors of our corpus, without distinction of national origin. Unsurprisingly, we encounter the themes addressed in the summits and the reports: the hopes created by the technology for the treatment of certain diseases, the development of more resistant and productive plants, governance issues and the role of the public. The description of the method and its targets also remains present. But a difference is nonetheless visible: the 
publications discuss more concrete applications of gene editing (i.e., specific diseases or certain edible plants).

\section{Benefits and Concerns Discussed}

We subsequently separated the articles according to the countries of academic affiliation of their authors. Most authors underline the benefits that gene editing can generate. But there are notable differences depending on the country of academic origin of the authors. If we look at individual countries, we observe that UK authors highlight the advances regarding the autonomy of reproduction due to the possibility of modifying and improving embryos and US authors underline the possibility to fight against some of the consequences of climate change, in particular drought tolerance.

If we look at groups of countries, we see a reflection that is focused on gene or medical therapies (Canadian, Australian, Japanese and US authors), on certain rare genetic diseases, complex diseases or cancers (Australian, Canadian, US, and Japanese authors) and on fertility, reproduction and parenthood (Canadian and US authors). Some articles refer to the dignity and fundamental human rights at stake. Likewise, many publications in our corpus evoke the progress made (and to come) regarding plants and animals. These advances, described as the "fourth agricultural revolution" (by a UK author) or a "revolution" (German authors) are considered as significantly promising in terms of food security (Chinese authors) and the source of further innovations to come (German authors). While we see that the benefits of gene editing are discussed across countries, there are differences in terms of what benefits in particular gene editing might yield.

As much as different kinds of benefits are discussed in the publications, so are concerns. These concerns can be qualified as general and ubiquitous, since we find them almost uniformly shared in the articles we have studied. There are warnings about the risks of an uncontrolled deployment of gene editing in humans, but also in plants and animals. The technique remains ethically "controversial" and "immature" (Chinese authors). The potential risks to be mastered with regard to safety and human health (Australian, UK and Japanese authors), as well as for the safeguarding of wildlife, in particular due to uncertainties and risks regarding the "safety" of the method (Canadian and German authors), are seen as decisive for a large-scale dissemination and application of the technology. Some authors pay special attention to the "future generations" (Australian and German authors) - German authors being in line here with the German report's focus on "social justice." It is thus argued that as of today, societies must equip themselves with tools to measure the "risks" (German and Japanese authors), and take into account "uncertainties" (German authors) to remove the threat to human health posed by the new method. Such a framing of science in terms of benefits and risks has been criticised by a number of scholars and actors, for it narrows down the issue to a very technological and scientific debate at the expense of a wider, more social and democratic debate (Wickson and Wynne 2012; Helliwell et al., 2019).

\section{Governance and its Geographies}

Given these concerns and benefits, how is gene editing to be governed? All the authors in our corpus recognize the need to build a framework, whether an ethical, legal and/or moral one. But how should the geographical frame of this framework be defined? Should it be national, transnational, and/or international?

Unsurprisingly, He's announcement of the birth of the twins Lulu and Nana, whose genome was altered via gene editing, is discussed in many publications. It is argued that this event has raised the question about "where to draw the line" (Australian authors), putting to the test the old model of GMO regulation (UK, German, Australian and Chinese authors) that most countries or unions of countries have historically adopted. In order to respond to this problem, certain publications favor the implementation of the "precautionary principle" (Australian authors), considered as the prerequisite of moral responsibility and making it possible to manage a potential threat in a situation of uncertainty. As such, the European model of the precautionary principle is often cited as an example, as is the 2018 ruling of the EU Court of Justice (which states that products resulting from gene editing are considered as GMOs).

The European framework makes it possible to impose a certain number of rules on its member states. Concerning those nations not integrated within larger unions, it is argued that it is important that they develop their own existing legal frameworks which are sometimes considered obsolete, and put to the test by the rapid evolution of innovations in biotechnology (UK and Canadian authors) and work within a framework of "responsible innovation" (UK and US authors). The UK authors of our corpus join the vision that emerged from the UK and Australian reports analyzed previously: it is preferable to develop the existing national legal framework first, before agreeing at the international level. However, many authors of our study insist on the fact that regulation and governance need to happen on an international level - "international" and "global" are the geographical terms with most occurrences in our corpus (see Table 4). Such a "global" (Japanese authors), "international" (German authors), or "transnational" (Canadian authors) framework would be the response to a society and a policy that have also become global (Japanese authors) - and an international harmonization of legal standards is needed (German authors). It is argued that China needs to develop its own regulations in coordination with other countries (Canadian authors). The discussion also insists on the importance of scientific organizations, who should adopt a sort of political management of risk and should also seek for coordinated action at the transnational level (Canadian, UK and German authors).

If we analyse the active forms with most occurrences in our corpus, we see that three families of geographical terms are prominent: 1) the international level (with terms such as "international," "global," "world," "worldwide," "transnational"), 2) the national level (with "national," "country," "United Kingdom," "China," "Chinese," "American," "Nation"), and 3) Europe ("EU," "European," "Europe") (see Table 4). In addition, there are also 
TABLE 4 | Active forms about space/geography with their occurrences.

Global 28; International 26; EU 23; National 18; World 15; Line 12; European 11; United Kingdom 11; Country 10; China 10; Chinese 9; Barrier 7; Europe 6; Transnational 6; Worldwide 5; Space 5; American 4; Nation 3; Boundary 3; Landscape 3; Internationally 3; Globally 3; Border 3; Americans 3; Australia 3

geographical terms in our corpus that are used in more metaphorical ways, such as line, barrier, space, and landscape. It is interesting to note that each of these terms is used in specific ways. The term line is used - apart from its occurrence in the "germline" and expressions such as "in line with" or "lines of inquiry" - to talk about legality and ethics: a "line" that is "drawn" and should "not be crossed" between editing somatic cells and editing the germline. The term barrier is often used to talk about socio-economic issues ("trade barriers," "diplomatic barriers"), while landscape is above all used to talk about the regulation of gene editing (the "regulatory landscape," seen as "complex," "mosaic," and "diverse"). Finally, space is mostly used to refer to public debate and democracy. We see here that multiple scales are at stake and that even the choice of words to describe the cultural spaces of gene editing need to be situated and contextualized. Science is not only produced and negotiated in space-a now common theme running through science studies-it is also governed and debated across diverse, multi-layered and fragmented spatialities.

\section{Positioning the Public}

The public is sometimes constructed in a rather narrow way. For instance, it is described as "recalcitrant" by US, UK and German authors. Terms such as "acceptance" (10 occurrences), “acceptable” (10), “accept” (9), and "acceptability" (4) are used and the perceived challenge is to educate, inform and convince the public of the positive features of gene editing. We have argued elsewhere that, in papers by Japanese authors for example, the public is referred to as an actor that "must accept" (Meyer 2020). Such a positioning stands in stark contrast to a vision of the public that is not perceived as ignorant or irrational but as an entity to be consulted. This finding is particularly noteworthy, since despite many calls for a rethinking and involvement of the public-and even the presence of papers by science studies scholars in our corpus-the public is still often portrayed as an actor that needs to accept scientific progress.

However, most authors condemn a conception of gene editing that does not consider the importance of the role of political and scientific governance. The need to involve civil society in the establishment of a public debate is underlined, in order to build an ethics around collectively accepted principles [visible through terms such as "involve" (15 occurrences), "engagement" (13), "engage" (11), and "dialogue" (2)]. In order to create such a democratic debate (US authors), the publications we have studied advocate for a greater integration of the public and of NGOs (UK authors), for increasing the engagement and participation of actors in ongoing debates (Canadian, UK and Japanese authors), for creating spaces for exchange (US authors) to facilitate discussion and develop interactions (UK authors) and find a consensus (Japanese authors) between experts and lay people.
Such a consideration for the public is not uncommon today; scholars have observed that decision-making processes within institutions and governments have significantly opened through public engagement and participation (see Irwin 2006; Chilvers and Kearnes, 2015). This new and more inclusive form of governance promotes a more active role for the public. Many actors have thus called for public debate on gene editing, be it the WHO, the UK Nuffield Council on Bioethics, or various other scientific institutions and academies.

\section{DISCUSSION}

This article has traced the contours and dynamics of the debates about the politics of gene editing by providing both a quantitative and qualitative analysis of the publications on the topic. Our scientometric analysis of scientific articles published between 2013 and 2020 shows that the governance and regulation of gene editing is discussed across an increasing range of disciplines and countries over the years. More disciplines become involved, with fewer articles in biology journals and a recent increase of articles from the social sciences. During the same period, the debate becomes more international, with proportionally fewer articles from North America and the number of contributing countries being multiplied by 9.5. Despite this opening up, discussions are still predominantly located in Europe and North America and in a few key domains, such as biology, genetics and the social sciences.

If we look at the content of the publications, be it scientific publications or reports, we observe a striking homogeneity. Several themes are recurrent, such as ethics, governance, and public debate. The general framing of the debate about the politics of gene editing is something almost universally shared. Within this frame, the benefits and risks of gene editing are discussed at great length. But while the benefits of gene editing are addressed across all the countries we studied, the specific kinds of benefits being discussed differ. The same counts for risks: while they are addressed in all the countries of our corpus, the ways in which they are approached does differ - with for instance some countries being more precautious than others.

We have refrained in this article from doing a strict comparison between countries. This would have led to two key shortcomings: we would have essentialised countries and have been tempted to provide cultural explanations for the differences observed; and our analysis would only have travelled between countries, but not within our corpus. What we have done was to trace the different kinds of arguments present, and how and where they are articulated. Importantly, this has enabled us to shed light on the different geographical scales mobilised in discussions. 
Several spatialities are visible in our corpus: the international level, the European Union, as well as individual nations. Accordingly, we have seen calls for "coordination" and "dialogue" among and across these different spatialities. At the same time, we have also seen that coordination might be difficult to achieve, given differences across countries and continents. But not only are there differences among countries in terms of their regulatory frameworks and modes of governance. Our analysis also points to "power" differentials between countries, with a relatively small number of countries and groups of countries that lead the debate - be it in terms of scientific output, reports or the times they are referred to. The United States, the United Kingdom, and Europe clearly stand out. The other country that stands out, albeit in a rather negative way, is China, mostly via discussions around He's experiments.

Our main contributions are the following ones. We offer the first lexicometric analysis of publications about gene editing, and, together with other contributions in this special issue (i.e., Kuzma and Cummings), we offer some of the first quantitative analyses of the topic. Our analysis shows that across the countries we studied there are, all in all, only a few differences in terms of how gene editing is discussed. The general framing of the debate is widely shared (further academic work might look at why this is the case, and scientists role in this). The differences that we have observed are rather marginal and specific ones, when the applications or benefits of gene editing are discussed, or when the importance of the economy or of involving the public is mentioned. We also contribute to the geography of science and science studies by researching the spatiality of science in a multilayered way. We have relied on a traditional geographic approach by analysing publications across the national affiliations of authors; we have traced the spatial terms that are mobilised and how they are used; and we have looked - in a more sociological reading of space - at the ways in which debates are framed and publics are positioned. We hold that bringing together multiple methods allows us to discuss the politics of gene editing in a richer and more multifaceted way, and that this opens up fertile dialogues between geography, sociology and political science.

\section{REFERENCES}

Akrich, M. (2019). Temporalité, régimes de participation et formes de communautés. Réseaux 214-215 (2), 25-66. doi:10.3917/res.214.0025

Baltimore, D., Berg, P., Botchan, M., Carroll, D., Charo, R. A., Church, G., et al. (2015). A Prudent Path Forward for Genomic Engineering and Germline Gene Modification. Science 348 (6230), 36-38. doi:10.1126/science.aab1028

Callon, M. (1999). The Role of Lay People in the Production and Dissemination of Scientific Knowledge. Sci. Techn. Soc. 4 (1), 81-94. doi:10.1177/ 097172189900400106

Cambrosio, A., Cointet, J.-P., and Abdo, A. H. (2020). Beyond Networks: Aligning Qualitative and Computational Science Studies. Quantitative Sci. Stud. 1 (3), 1017-1024. doi:10.1162/qss_a_00055

Chilvers, J., and Kearnes, M. (2015). Remaking Participation: Science, Environment and Emergent Publics. London, United Kingdom: Routledge.
Our findings are of course limited by our research design. We have analysed, via one open source program, the publications present in the Web of Science and selected seven countries within our corpus. Further research could thus examine the topic by searching other databases (i.e., Scopus, PubMed), selecting other countries (i.e., countries from the Global South) and use other programs (i.e., Hyperbase, TXM, VOSviewer) to do other kinds of analyses. Further research could also expand our research questions by analysing in more detail who speaks (what kinds of scientists, institutions, groups or committees are visible and/or authoritative in the debate - and how are they linked?) and how expertise is made, distributed and demarcated. We hold that the governance and regulation of gene editing is a fruitful terrain to be further explored in an empirical and interdisciplinary way and by bringing together qualitative and quantitative approaches.

\section{DATA AVAILABILITY STATEMENT}

The original contributions presented in the study are included in the article/Supplementary Material, further inquiries can be directed to the corresponding author.

\section{AUTHOR CONTRIBUTIONS}

MM contributed to the conception and theoretical problematization of the article and carried out the qualitative analysis. FV collected the data on scientific publications, while MM collected the data on reports. FV conducted the statistical and lexicometric analysis. FV and $\mathrm{MM}$ interpreted the scientometric results and FV interpreted the lexicometric results. MM wrote the first draft of the manuscript. All authors approved the submitted version.

\section{SUPPLEMENTARY MATERIAL}

The Supplementary Material for this article can be found online at: https:/www.frontiersin.org/articles/10.3389/fpos.2021.731496/ full\#supplementary-material

Cyranoski, D. (2019). Russian Biologist Plans More CRISPR-Edited Babies. Nature 570 (7760), 145-146. doi:10.1038/d41586-019-01770-x

Epstein, S. (1995). The Construction of Lay Expertise: AIDS Activism and the Forging of Credibility in the Reform of Clinical Trials. Sci. Technol. Hum. Values 20 (4), 408-437. doi:10.1177/016224399502000402

Fallery, B., and Rodhain, F. (2007). Quatre approches pour l'analyse de données textuelles: lexicale, linguistique, cognitive, thématique. Montreal, Canada: XVIème Conférence de l'Association Internationale de Management Stratégique AIMS, 1-16.

Frenken, K., and Leydesdorff, L. (2004). "Scientometrics and the Evaluation of European Integration," in Innovation, Entrepreneurship and Culture, The Interaction between Technology, Progress and Economic Growth. Editors T. E. Brown and J. M. Ulijn (Cheltenham: Edward Elgar publishing), 87-102. Frow, E. (2015). Reframing the Debate Around CRISPR and Genome Editing. Washington: Paper presented at the ASU Washington Center (Accessed December 9, 2015). 
Gieryn, T. F. (1999). Cultural Boundaries of Science: Credibility on the Line. Chicago: University of Chicago Press.

Gieryn, T. F. (1983). Boundary-work and the Demarcation of Science from Nonscience: Strains and Interests in Professional Ideologies of Scientists. Am. Sociol. Rev. 48 (6), 781-795. doi:10.2307/2095325

Glänzel, W., Debackere, K., and Meyer, M. (2008). 'Triad' or 'tetrad'? on Global Changes in a Dynamic World. Scientometrics 74 (1), 71-88. doi:10.1007/ s11192-008-0104-5

Helliwell, R., Hartley, S., and Pearce, W. (2019). NGO Perspectives on the Social and Ethical Dimensions of Plant Genome-Editing. Agric. Hum. Values 36 (4), 779-791. doi:10.1007/s10460-019-09956-9

Irwin, A. (2006). The Politics of Talk. Soc. Stud. Sci. 36 (2), 299-320. doi:10.1177/ 0306312706053350

Jasanoff, S., and Hurlbut, Bj. (2018). A Global Observatory for Gene Editing. Nature 555, 435-437. doi:10.1038/d41586-018-03270-w

Jasanoff, S., Hurlbut, B. J., and Krishanu, S. (2015). CRISPR Democracy: Gene Editing and the Need for Inclusive Deliberation. Issues Sci. Techn. 32 (1), 37-49.

Kato-Nitta, N., Maeda, T., Inagaki, Y., and Tachikawa, M. (2019). Expert and Public Perceptions of Gene-Edited Crops: Attitude Changes in Relation to Scientific Knowledge. Palgrave Commun. 5 (1), 1-14. doi:10.1057/s41599-0190328-4

Kelle, U. (2010). "The Development of Categories: Different Approaches in Grounded Theory," in The Sage Handbook of Grounded Theory (London: Sage), 191-213.

Kumari, L. (2006). Trends in Synthetic Organic Chemistry Research. CrossCountry Comparison of Activity Index. Scientometrics 67 (3), 467-476. doi:10.1556/scient.67.2006.3.8

Lahlou, S. (1994). L'analyse Lexicale. Variances 3, 13-24.

Lanphier, E., Urnov, F., Haecker, S. E., Werner, M., and Smolenski, J. (2015). Don't Edit the Human Germ Line. Nature 519 (7544), 410-411. doi:10.1038/519410a

Lassoued, R., Phillips, P. W. B., Smyth, S. J., and Hesseln, H. (2019). Estimating the Cost of Regulating Genome Edited Crops: Expert Judgment and Overconfidence. GM Crops Food 10 (1), 44-62. doi:10.1080/ 21645698.2019.1612689

Law, J. (2004). And if the Global Were Small and Noncoherent? Method, Complexity, and the Baroque. Environ. Plan. D 22 (1), 13-26. doi:10.1068/ $\mathrm{d} 316 \mathrm{t}$

Leydesdorff, L., Ràfols, I., and Milojević, S. (2020). Bridging the divide between Qualitative and Quantitative Science Studies. Quantitative Sci. Stud. 1 (3), 918-926. doi:10.1162/qss_e_00061

Liang, P., Xu, Y., Zhang, X., Ding, C., Huang, R., Zhang, Z., et al. (2015). CRISPR/ Cas9-mediated Gene Editing in Human Tripronuclear Zygotes. Protein Cell 6 (5), 363-372. doi:10.1007/s13238-015-0153-5

Livingstone, D. N. (2005). Putting Science in its Place: Geographies of Scientific Knowledge. Chicago: University of Chicago Press.

Macnaghten, P., and Habets, M. G. J. L. (2020). Breaking the Impasse: Towards a Forward-looking Governance Framework for Gene Editing with Plants. Plants People Planet. 2 (4), 353-365. doi:10.1002/ppp3.10107

Mali, F. (2020). Is the Patent System the Way Forward with the CRISPR-Cas 9 Technology? SerTS 33 (4), 2-23. doi:10.23987/sts.70114

Martin, P., Morrison, M., Turkmendag, I., Nerlich, B., McMahon, A., de Saille, S., et al. (2020). Genome Editing: the Dynamics of Continuity, Convergence, and Change in the Engineering of Life. New Genet. Soc. 39 (2), 219-242. doi:10.1080/14636778.2020.1730166

Mattsson, P., Laget, P., Nilsson, A., and Sundberg, C.-J. (2008). Intra-EU vs. ExtraEU Scientific Co-publication Patterns in EU. Scientometrics 75 (3), 555-574. doi:10.1007/s11192-007-1793-x

Meyer, M., and Heimstädt, C. (2019). The Divergent Governance of Gene Editing in Agriculture: a Comparison of Institutional Reports from Seven EU Member States. Plant Biotechnol. Rep. 13 (5), 473-482. doi:10.1007/ s11816-019-00578-5

Meyer, M. (2021). Taking Responsibility, Making Irresponsibility: Controversies in Human Gene Editing. Soc. Stud. Sci. Online first. doi:10.1177/ 03063127211025631

Meyer, M. (2020). The Fabric of the Public in Debates about Gene Editing. Environ. Commun. 14 (7), 872-876. doi:10.1080/17524032.2020.1811477
Meyer, M., and Vergnaud, F. (2020). The Rise of Biohacking: Tracing the Emergence and Evolution of DIY Biology through Online Discussions. Technol. Forecast. Soc. Change 160, 120206. doi:10.1016/j.techfore.2020.120206

Monroy, S. E., and Diaz, H. (2018). Time Series-Based Bibliometric Analysis of the Dynamics of Scientific Production. Scientometrics 115 (3), 1139-1159. doi:10.1007/s11192-018-2728-4

Morange, M. (2017). Human Germline Editing: a Historical Perspective. Hist. Philos. Life Sci. 39 (4), 34-10. doi:10.1007/s40656-017-0161-2

National Academies of Sciences, Engineering, and Medicine (2017). Human Genome Editing: Science, Ethics, and Governance. Washington, DC: National Academies Press.

National Academies of Sciences, Engineering, and Medicine (2019). Second International Summit on Human Genome Editing: Continuing the Global Discussion: Proceedings of a Workshop in Brief. Washington, DC: The National Academies Press.

Nuffield Council on Bioethics (2016). Genome Editing: An Ethical Review. Nuffield Council on Bioethics.

Parthasarathy, S. (2015). Governance Lessons for CRISPR/Cas9 from the Missed Opportunities of Asilomar. Ethics in Biol. Eng. Med. Int. J. 6 (3-4), 305-312. doi:10.1615/ethicsbiologyengmed.2016016470

Ratinaud, P. (2021). IRAMUTEQ: Interface de $\mathrm{R}$ pour les Analyses Multidimensionnelles de Textes et de Questionnaires[Software]. Version 0.7 alpha 2. GNU General Public License. Available at: http://www.iramuteq.org. (Accessed September 15, 2021).

Reinert, A. (1983). Une méthode de classification descendante hiérarchique: application à l'analyse lexicale par contexte. Cahiers de l'Analyse des Données 8 (2), 187-198.

Reinert, M. (1990). Alceste une méthodologie d'analyse des données textuelles et une application: Aurelia De Gerard De Nerval. Bull. Sociol. Method./Bulletin de Méthodologie Sociologique 26 (1), 24-54. doi:10.1177/075910639002600103

Reinert, M. (1986). Un Logiciel D'analyse Lexicale. Cahiers de l'analyse des données 11 (4), 471-481.

Shapin, S. (1998). Placing the View from Nowhere: Historical and Sociological Problems in the Location of Science. Trans. Inst. Br. Geog. 23 (1), 5-12. doi:10.1111/j.0020-2754.1998.00005.x

Thornberg, R., and Charmaz, K. (2014). "Grounded Theory and Theoretical Coding," in The Sage Handbook of Qualitative Data Analysis (London: Sage), 153-169.

Wang, Q., and Waltman, L. (2016). Large-scale Analysis of the Accuracy of the Journal Classification Systems of Web of Science and Scopus. J. Inform. 10 (2), 347-364. doi:10.1016/j.joi.2016.02.003

Wickson, F., and Wynne, B. (2012). The Anglerfish Deception. EMBO Rep. 13 (2), 100-105. doi:10.1038/embor.2011.254

Yan, P., and Mitcham, C. (2020). The Gene-Edited Babies Controversy in China: Field Philosophical Questioning. Soc. Epistemol. 35, 1-14. doi:10.1080/ 02691728.2020 .1752842

Zhang, X., Chen, A., and Zhang, W. (2021). Before and after the Chinese GeneEdited Human Babies: Multiple Discourses of Gene Editing on Social media. Public Understanding Sci. 30 (5), 570-587. doi:10.1177/0963662520987754

Conflict of Interest: The authors declare that the research was conducted in the absence of any commercial or financial relationships that could be construed as a potential conflict of interest.

Publisher's Note: All claims expressed in this article are solely those of the authors and do not necessarily represent those of their affiliated organizations, or those of the publisher, the editors and the reviewers. Any product that may be evaluated in this article, or claim that may be made by its manufacturer, is not guaranteed or endorsed by the publisher.

Copyright (c) 2021 Meyer and Vergnaud. This is an open-access article distributed under the terms of the Creative Commons Attribution License (CC BY). The use, distribution or reproduction in other forums is permitted, provided the original author(s) and the copyright owner(s) are credited and that the original publication in this journal is cited, in accordance with accepted academic practice. No use, distribution or reproduction is permitted which does not comply with these terms. 